\title{
Os Livros didáticos e a História da participação das mulheres no
}

\author{
Movimento Estudantil \\ The textbooks and History of women's participation in the Student Movement
}

\author{
Prof. Dr. Vanderlei Machado ${ }^{1}$ \\ Profa. Dra. Carla Simone Rodeghero ${ }^{2}$
}

\begin{abstract}
Resumo: Neste artigo buscamos perceber e analisar a maneira como os livros didáticos de história narram, através de textos e de imagens, a participação feminina no movimento estudantil brasileiro entre $1964 \mathrm{e}$ 1968. Com este objetivo, analisamos onze livros didáticos de História distribuídos pelo Governo Federal para as escolas públicas através do Programa Nacional do Livro Didático para o Ensino Médio, PNLEM/2008. Além disso, apresentaremos um levantamento de livros e de trabalhos acadêmicos que abordam a participação das mulheres nas lutas do movimento estudantil. Percebemos que vem crescendo o número de pesquisas que abordam a história da participação feminina no movimento estudantil. Nestas predomina o uso da categoria gênero de análise histórica e da história oral como metodologia de pesquisa. Apesar desta constatação, ainda são poucas as referências veiculadas nos livros didáticos sobre a participação feminina no movimento estudantil.
\end{abstract}

Palavras-chave: Livro didático de História; Movimento Estudantil; História das Mulheres

\begin{abstract}
In this article we seek to perceive and analyze the way in which the textbooks of history narrate, through texts and images, the female participation in the Brazilian student movement between 1964 and 1968. With this objective, we analyzed eleven textbooks of History distributed for public schools through by the National High School Textbook Program, PNLEM / 2008. In addition, we will present a survey of books and scholarly works that address the participation of women in the struggles of the student movement. We have noticed that the number of studies that address the history of female participation in the student movement has increased. In these, the use of the category of historical analysis and oral history as research methodology predominates. Despite this, there are still few references in the textbooks on female participation in the student movement.
\end{abstract}

Keywords: History textbook; Student Movement; History of Women

\section{Introdução}

O presente artigo busca perceber e analisar a maneira como os livros didáticos de história narram, através de textos e de imagens, a participação feminina no

\footnotetext{
${ }^{1}$ Vanderlei Machado (vandermachado@ hotmail.com). Doutor em História e Professor Titular do Departamento de Humanidades do Colégio de Aplicação da Universidade Federal do Rio Grande do Sul (UFRGS).

${ }^{2}$ Carla Simone Rodeghero (carla.simone@ufrgs.br) Doutora em História e Professora do Departamento de História e do Programa de Pós-Graduação em História da Universidade Federal do Rio Grande do Sul (UFRGS).
} 
movimento estudantil, notadamente, entre 1964 e 1968. ${ }^{3}$ Para isto iremos analisar um conjunto de onze livros didáticos de História distribuídos pelo Governo Federal para as escolas públicas através do Programa Nacional do Livro Didático para o Ensino Médio, PNLEM/2008, concentrando nossa atenção nos capítulos que abordam a história do Brasil no período compreendido entre o golpe de 1964 e a publicação do Ato Institucional de n. 5 (AI 5), em dezembro de 1968.

Além de atentar para a maneira como os livros didáticos de história narram a participação feminina no movimento estudantil, apresentaremos um levantamento de livros e de trabalhos acadêmicos que abordam a participação das mulheres no movimento estudantil, no período em estudo. Este levantamento, acreditamos, pode contribuir para que a temática seja aprofundada em sala de aula pelos/as professores/as de história.

O Programa Nacional do Livro Didático para o Ensino Médio, segundo Paulo Knauss (2009, p. 296), inseriu-se no movimento de renovação das políticas públicas para a educação básica no Brasil, estendendo ao Ensino Médio o mesmo modelo de tratamento que vinha sendo dado aos livros didáticos do Ensino Fundamental, através do Programa criado em 1985. ${ }^{4}$ Os livros do Programa Nacional do Livro Didático (PNLD), após passarem por uma avaliação e indicação pelo MEC, são selecionados pelos professores e professoras para serem adquiridos e distribuídos para os/as estudantes das escolas públicas que os utilizarão durante três anos.

Em 2008, o Governo Federal distribuiu pela primeira vez os livros didáticos de história para o Ensino Médio. Naquele mesmo ano ocorreu em todo o Brasil uma série de eventos acadêmicos e culturais que buscaram rememorar os acontecimentos que marcaram o ano de 1968, no Brasil e no mundo. Entre eles, as lutas do movimento estudantil que levaram a juventude a ocupar as ruas de várias cidades ao redor do planeta.

Buscando perceber como os livros didáticos de história distribuídos pelo PNLEM/2008 abordaram a participação das mulheres no movimento estudantil brasileiro, analisamos um conjunto de livros didáticos de História para o Ensino Médio, denominados

\footnotetext{
${ }^{3}$ Este texto é resultado de uma pesquisa mais ampla intitulada "A história das mulheres que os livros didáticos não contam: as lutas femininas contra a ditadura militar no Brasil”, iniciada em 2009 e coordenada pelo Prof. Doutor Vanderlei Machado. Esta pesquisa conta com a colaboração da Profa. Dra. Carla Simone Rodeghero (Departamento e PPG em História-UFRGS). Ao longo desta pesquisa contamos com a participação dos bolsistas de Iniciação Científica: Alessandro Güntzel, Bernard Goulart Prietto e Isadora Librenza. Agradecemos a Profa. Dr. Luciana Rossato (Departamento e PPG em História-UDESC) pela leitura e comentários ao texto.

${ }^{4}$ O Programa Nacional do Livro Didático (PNLD) foi criado pelo Decreto 9154, de 01/08/1985.
} 
"livro do professor". 5 Estes são distribuídos pelas editoras com a finalidade de influenciar na escolha do livro do aluno a ser adotado pelas escolas. Analisamos onze livros didáticos, de um total de dezenove livros indicados. ${ }^{6}$ Os demais não foram enviados pelas distribuidoras, apesar de termos solicitado o material. Os manuais analisados, na sua maioria, foram publicados no ano de 2005, na cidade de São Paulo.

Segundo o Catálogo do PNLEM/2008, entre os critérios utilizados na seleção estava a necessidade desse material abordar "criticamente as questões de sexo e gênero" (PNLEM 2008, p.15). Este documento oficial, assim com outros documentos que tratam da educação no Ensino Médio, não explicita como está entendendo o termo gênero. Parece haver nesse documento um entendimento de que gênero é sinônimo de sexo. Segundo Joan Scott, o termo gênero é utilizado, entre outras possibilidades para:

\begin{abstract}
"designar as relações sociais entre os sexos. Seu uso rejeita explicitamente explicações biológicas [...] o termo "gênero torna-se uma forma de indicar "construções culturais" - a criação inteiramente social de ideias sobre os papeis adequados aos homens e às mulheres. Trata-se de uma forma de se referir às origens exclusivamente sociais das identidades subjetivas de homens e de mulheres. 'Gênero' é, segundo esta definição, uma categoria social imposta sobre um corpo sexuado" (SCOTT , 1995, p.75).
\end{abstract}

Esta abordagem, como procuraremos demonstrar, não é empregada nos textos sobre o movimento estudantil presentes nos livros didáticos aqui analisados. Porém, isso não significa que as mulheres estejam completamente ausentes dos livros didáticos de história. Ana Maria Marques, num artigo intitulado Gênero e ensino de história: estudo sobre livros didáticos e práticas docentes no ensino médio, analisou oito livros didáticos de história do ensino médio e constatou que os mesmos mencionam a presença de mulheres em diversos contextos

\footnotetext{
${ }^{5}$ O Livro do Professor é composto pelo Livro do Aluno e por outro material que recebe diferentes denominações e que tem como objetivo apresentar para os professores as opções teóricos metodológicas do texto bem como orientações de como utilizá-lo em sala de aula.

${ }^{6}$ Dos dezenove livros didáticos de história indicados pelo catálogo do Programa Nacional do Livro didático para o Ensino Médio, PNLEM/2008, 14 são volumes único e cinco são coleções, destas somente o terceiro volume foi analisado no presente estudo. Como os volumes seguem uma história linear, que vai da pré-história à história recente, é no terceiro volume que a história do século XX é apresentada.
} 
históricos. A autora percebeu que todas as mulheres "citadas de forma recorrente nos remetem para uma 'história de governantes e batalhas', que vem de uma tradição positivista ou empirista e acaba por valorizar mulheres que ocupam posições tradicionalmente masculinas" (MARQUES, 2015, 215). Em nenhum momento do seu trabalho, porém, Ana Maria Marques mencionou o movimento estudantil ou mulheres que tenham participado do mesmo. Apesar disto, a autora fornece informações importantes para o presente estudo.

Vejamos, então, como os livros por nós analisados apresentam a participação feminina no movimento estudantil, no período em tela. Para realizar esta análise elaboramos um "Roteiro de Avaliação do Livro Didático" (Anexo I).

\section{Histórias do movimento estudantil: em busca da participação feminina}

Dos onze livros analisados, dez fazem alguma menção ao movimento estudantil e às suas manifestações contra a ditadura militar no Brasil, notadamente, daquelas que ocorreram ao longo do ano de 1968. Porém, nenhum livro didático coligido apresenta um título ou subtítulo de capítulo com referência expressa ao movimento estudantil brasileiro. A história do movimento estudantil aparece, geralmente, de maneira sucinta. Apesar disso, o fato da maioria dos livros mencionarem os temas relacionados ao movimento estudantil, notadamente, as manifestações ocorridas no ano de 1968, demonstra a importância do mesmo no contexto histórico em análise.

Nos manuais escolares analisados depreende-se que o movimento estudantil era formado por jovens do sexo masculino. Chegamos a esta conclusão a partir da constatação de que a maioria dos livros didáticos, ao discorrerem sobre o movimento estudantil, faz uso de termos masculinos genéricos como "estudantes" e "jovens". Porém, vale lembrar, as grandes manifestações de rua que tomaram as avenidas das cidades brasileiras no ano de 1968 eram formadas por homens e mulheres representantes de várias categorias de trabalhadores/as e de distintas faixas etárias, bem como líderes sindicais, intelectuais, artistas e o clero.

A relação entre movimento estudantil e juventude aparece na descrição feita no livro didático A escrita da História. Ali, pode-se ler que "o movimento estudantil, [agia] em sintonia com a rebeldia dos jovens norte-americanos e europeus da época" (CAMPOS; MIRANDA, 2005, p. 586). Nesta parte do texto se faz referência às grandes manifestações que marcaram o ano de 1968 em várias partes do mundo. Naquele contexto, articulando 
"reivindicações específicas aos grandes temas nacionais, os estudantes organizaram grandes manifestações exigindo o fim da ditadura militar." O texto informa ainda sobre os confrontos ocorridos entre manifestantes e policiais, a invasão de universidades e centros culturais e a prisão e o "espancamentos de professores, estudantes, artistas e intelectuais" (CAMPOS; MIRANDA, 2005, p.587). Nenhuma referência direta é feita à presença de mulheres nesses acontecimentos mencionados.

Esse silêncio, em relação à participação feminina no movimento estudantil, é rompido no livro Nova História Crítica no qual está registrado que "contra os meninos e meninas do movimento estudantil, foram lançados homens armados até os dentes" (SCHMIDT, 2005, p. 740). Após esta rápida menção às "meninas" volta-se a fazer uso de termos no masculino genérico como "os estudantes". Nada ficamos sabendo sobre as formas de participação das "meninas" no movimento estudantil. Porém, os termos "meninas" e "meninos", nos remetem novamente para a relação entre movimento estudantil e juventude.

A morte do estudante secundarista Edson Luís, em março de 1968, no Rio de Janeiro desencadeou uma série de passeatas e de manifestações nas principais cidades brasileiras. Este fato foi mencionado em sete dos onze livros analisados. A morte ocorreu após os estudantes, que "protestavam por melhoria da qualidade da comida servida no restaurante Calabouço, ligado à Universidade Federal do Rio de Janeiro, entrarem em choque com a polícia" (AZEVEDO; SERIACOPI, 2007, p. 481). Os manuais analisados utilizaram formas diferentes para se referirem ao estudante morto na ação policial e para informar a sua idade. Edson Luís é descrito no livro Nova História Crítica como "um rapaz" (SCHMIDT, 2005, p. 740); o manual História: das cavernas ao terceiro milênio afirma se tratar de "um jovem de 16 anos" (MOTA; BRAICK, 2005, p. 159); o livro História menciona o "jovem Edson Luís de Lima Souto, de 17 anos" (AZEVEDO; SERIACOPI, 2007, p. 481) e a obra Rumos da História se refere ao "estudante Edson Luís, de 18 anos" (REZENDE; DIDIER, 2005, p. 619). A suposta idade de 18 anos aparece também no livro didático História Global: Brasil e Geral (COTRIM, 2005, p. 559). No livro História faz-se menção ao fato de que Edson Luís era um "estudante secundarista" (FIGUEIRA, 2005, p. 378) e, por fim, o livro História do mundo ocidental menciona simplesmente o "estudante Edson Luís" (PEDRO; LIMA; CARVALHO, 2005, p. 479). Sobressai nestas citações, apesar das diferentes idades, a juventude do estudante morto.

O historiador João Roberto Martins Filho, em seu artigo $O$ movimento estudantil dos anos 1960, assinala que em 28 de março de 1968 ocorreu um confronto entre "estudantes, na 
sua maior parte secundaristas, e um pelotão da Polícia Militar da Guanabara, ao lado do restaurante estudantil conhecido como Calabouço". Os estudantes, secundaristas e universitários, reclamavam da má qualidade da alimentação servida naquele local. A ação da polícia, continua o autor, "resultou na morte de um estudante - Edson Luís Souto, abatido por um tiro." Mais adiante, somos informados de que tratava-se de um "jovem secundarista" (MARTINS FILHO, 2007, p. 195).

A morte do estudante secundarista foi um dos acontecimentos que marcaram o movimento estudantil no ano de 1968, antes do AI 5, quando as passeatas denunciando os crimes cometidos pela repressão ainda eram toleradas. O livro História afirma que "a maior mobilização popular contra o regime militar partiu dos estudantes". Neste manual é mencionado ainda que no ano de 1968 a "agitação estudantil eclodiu em várias partes do mundo" e que os "jovens saíam às ruas para combater questões como as formas tradicionais de ensino, o racismo, a Guerra do Vietnã, a repressão sexual e o controle da mulher pelos homens" (FIGUEIRA, 2005, p. 378). Ou seja, o autor nos remete para o fato de que, além de questões relacionadas à política e ao ensino, havia o desejo de se discutir temas comportamentais e as relações entre homens e mulheres.

Discorrendo sobre as transformações nos costumes que ocorreram no ano de 1968, o escritor Zuenir Ventura lembra que naquele ano discutiam-se, entre outros temas comportamentais, a necessidade da educação sexual nas escolas brasileiras e a questão da pílula e dos anticoncepcionais. Além disso, informa o autor, o cinema nacional passou a conter mais cenas de sexo. Com o mercado editorial não foi diferente, de tal forma que livros, jornais e revistas passaram a dar mais destaque para assuntos relativos à sexualidade. A propósito da "revolução sexual", que ocorreu no final dos anos 1960, Ventura avalia que, quando vista a distância, "lembra mais uma explosão de vontade e intenções do que de realizações. Provavelmente, falava-se e escrevia-se mais do que se fazia sexo. Como em geral só se fala de liberdade na sua ausência, a liberação era mais aparente do que real" (VENTURA, 1988, p. 31). Estes assuntos, como buscaremos explicar a seguir, também eram de interesse de pessoas envolvidas nas lutas estudantis. Porém, no livro didático citado acima não fica demonstrado como estas bandeiras de luta por igualdade entre homens e mulheres apareciam na pauta do movimento estudantil brasileiro.

Na obra Mulheres e Militantes, encontros e confrontos durante a ditadura militar, Gianordoli-Nascimento, Trindade e Santos nos lembram que os/as militantes e simpatizantes de esquerda costumavam debater as mudanças dos costumes em mesas de bar. A discussão 
sobre a "liberdade sexual, o uso da pílula, a liberdade de ação para as mulheres eram pautas permanentes de discussão nos encontros informais da militância estudantil" (GIANORDOLINASCIMENTO, et al., 2012, p. 131).

A historiadora Maria Paula Araújo, em seu livro sobre a história da UNE, transcreve uma entrevista de história oral realizada com Maria Augusta Ribeiro relatando como esta vivenciou a liberdade sexual nos anos 1960:

"Naquela época não tinha AIDS, ainda bem! Já era a época da pílula, que já foi uma conquista de liberdade muito grande. Então, tinha uma coisa libertária. Esse negócio de que a gente estava namorando um, mas gostava de outro. Transava mesmo! (RIBEIRO, Apud: ARAÚJO, 2007, p. 188).

Possivelmente esse comportamento "libertário", tão valorizado por Maria Augusta Ribeiro, não era compartilhado por todas as moças e rapazes que participaram do movimento estudantil. Vale destacar que algumas entidades estudantis eram vinculadas à Igreja Católica, como a JEC (Juventude Estudantil Católica) e a JUC (Juventude Universitária Católica), que tiveram grande influência entre os estudantes, notadamente no início dos anos 1960. Sobre esta questão o sociólogo Betinho nos informa que "os militantes da JEC e da JUC só se permitiam ter ato sexual com o casamento." (CAVALCANTI; RAMOS, 1978, p.70). Certamente, a sexualidade foi vivenciada de maneira diferenciada pelos/as militantes das diversas organizações estudantis, de diferentes gerações e nos distintos contextos históricos que marcaram os agitados anos 1960.

Retornando aos livros didáticos, o livro História chama atenção do/a leitor/a para o fato de que no "Brasil, a força do movimento foi maior entre os estudantes universitários" (FIGUEIRA, 2005, p. 378). Neste manual reforça-se esta ideia ao afirmar que os "estudantes estavam mobilizados em torno de entidades representativas como a UNE", que desde 1964 havia sido colocada na ilegalidade e realizou o seu XXX Congresso, em Ibiúna, no estado de São Paulo, de forma clandestina (FIGUEIRA, 2005, p. 379). O que não se menciona é que ao invadir o Congresso da UNE a repressão prendeu 800 estudantes, ${ }^{7}$ moças ${ }^{8}$ e rapazes, de vários estados brasileiros.

\footnotetext{
${ }^{7}$ Conforme Antonio Mendes Jr., em outubro de 1968 aconteceu o XXX Congresso da UNE, em Ibiúna, cidadezinha próxima a São Paulo. Durante a realização do mesmo, as forças da repressão invadiram o sítio onde
} 
Dez livros didáticos, dos onze analisados, fazem alguma referência à UNE. Entre as alusões à entidade estudantil universitária menciona-se a política cultural (PETTA; OJEDA; DELFINI, 2005, p. 319); o "fechamento da UNE” (PEDRO; LIMA; CARVALHO, 2005, p. 478); a continuação da atuação da UNE "mas na ilegalidade" (REZENDE; DIDIER, 2005, p. 619); a resistência da UNE ao acordo MEC-Usaid (SCHMIDT, 2005, p. 736); a realização, em 1968, de um Congresso clandestino, em Ibiúna, "para rearticular a União Nacional dos Estudantes" (MORAES, 2005, p. 419); a prisão dos "seus delegados" (MOTA; BRAICK, 2005, p. 160); a invasão da polícia e a prisão de "centenas de estudantes, entre eles Luís Travassos, presidente da UNE, José Dirceu, presidente da União Estadual dos Estudantes de São Paulo e Vladimir Palmeira, ex-presidente da União Metropolitana dos Estudantes do Rio de Janeiro" (AZEVEDO; SERIACOPI, 2007, p. 481). Somente este último livro didático menciona a participação de outras entidades, que não a UNE, no Congresso de Ibiúna.

A centralidade conferida à UNE pode nos levar a pensar a mesma como sendo sinônimo de movimento estudantil. Porém, este era formado por diversas entidades. Entre elas a UNE (União Nacional dos Estudantes), a UBES (União Brasileira dos Estudantes Secundaristas), a UME (União Metropolitana dos Estudantes), a AMES (Associação Metropolitana dos Estudantes Secundários), os DCEs (Diretórios Centrais dos Estudantes), os Grêmios Estudantis, entre outras organizações estudantis, universitárias e secundaristas.

A UNE teve a sua sede, no Rio de Janeiro, incendiada logo após o golpe de 1964. No final daquele ano, o ministro da Educação, Flávio Suplicy de Lacerda, anunciou que o governo federal pretendia extinguir a UNE, as UEEs e os diretórios estudantis (MARTINS FILHO, 2007, p. 190). A partir de então, a União Nacional dos Estudantes passou a atuar clandestinamente. Apesar de se encontrar na ilegalidade, "a UNE ainda permanecia como um símbolo importante para os estudantes" (MÜLLER; REZENDE, 2011, p. 62).

Em 1965 ocorreu a reconstrução das entidades estudantis e no segundo semestre de 1966 “o movimento estudantil renascente entraria em choque mais direto com as políticas da ditadura militar" (MARTINS FILHO, 2007, p. 193). Em 1967, Os estudantes se manifestaram

\footnotetext{
o evento acontecia e prenderam os/as 800 estudantes presentes. Ver: MENDES Jr, Antonio. Movimento Estudantil Brasileiro. São Paulo: Editora Basiliense, 1981, p. 86.

${ }^{8}$ Os nomes e as fotos das moças que participaram do Congresso da UNE, em 1968, na cidade de Ibiúna, podem ser acessados no sítio: Documentos Revelados. As meninas de Ibiúna. Galeria de fotos das estudantes presas no Congresso da UNE, em 1968. Disponível em: http://www.documentosrevelados.com.br/geral/as-meninas-deibiuna-galeria-de-fotos-das-estudantes-presas-no-congresso-da-une-em-1968/. Acesso em 18/01/ 2017.
} 
contra o acordo MEC-USAID, ${ }^{9}$ por mais vagas nas universidades, pela ampliação da moradia estudantil e pela manutenção e expansão dos restaurantes universitários. O ano de 1968 foi o ponto culminante de todas essas lutas estudantis e a morte do estudante Edson Luís, como nos lembra Maria Paula Araujo, "marcou o início de um processo de radicalização política e de confrontos violentos entre a polícia e os estudantes (ARAÚJO, 2007, p. 167).

Embora um secundarista tenha sido morto pela repressão, os livros didáticos analisados nada nos informam sobre a participação de entidades estudantis secundaristas como a UBES, ${ }^{10}$ a AMES e os Grêmios Estudantis, nas manifestações que ocorrem nas principais cidades brasileiras, notadamente, no ano de 1968. Este silêncio, acreditamos, está relacionado com a falta de publicações e trabalhos acadêmicos que analisem e descrevam a história do movimento estudantil secundarista em nível nacional.

Após analisar os textos dos livros didáticos que mencionam o movimento estudantil brasileiro, percebemos que os mesmos abordam esta história de maneira bastante fragmentada e resumida. Percebe-se uma centralidade nos acontecimentos ligados ao movimento estudantil que marcaram o ano de 1968. Um manual menciona o desejo de mudanças na relação entre homens e mulheres e a luta contra a "repressão sexual", porém, o mesmo não indica relações entre esses temas e as experiências que estavam sendo vividas pelos rapazes e moças que atuavam no movimento estudantil. Além disso, percebe-se que a utilização de termos genéricos como "jovens" e "estudantes" contribui para invisibilizar a história da participação das mulheres nas lutas estudantis. Apenas o livro Nova História Crítica fez menção às "meninas" do movimento estudantil. Porém, sem descrever como elas participaram das lutas e organizações.

Esta ausência das mulheres na história do movimento estudantil pode ser entendida quando nos remetemos para o trabalho de Ana Maria Marques, citado no início deste texto, que nos informa que os livros didáticos acabam dando visibilidade para as mulheres que se

\footnotetext{
${ }^{9}$ Segundo Rodrigo Patto Sà Motta a "sigla Usaid (United States Agency for International Development) é bem conhecida no Brasil, sobretudo por causa do impacto dos protestos antiditatoriais de fins da década de 1960. Naqueles anos, a expressão foi popularizada pelos grupos que conduziram manifestações de rua contra o governo militar, liderados principalmente por estudantes. Eles clamavam contra os acordos relacionados ao Ministério da Educação e Cultura (MEC-Usaid), firmados pelo governo com o propósito de usar assessoria norte-americana na reforma do ensino superior. Os acordos MEC-Usaid tornaram-se o principal símbolo do aumento da presença americana no Brasil após o golpe militar de 1964 e, por isso, forneceram argumento importante nas manifestações anti-imperialistas e antiamericanas." Conforme: MOTTA, Rodrigo Patto Sá. Modernizando a repressão: a Usaid e a polícia brasileira. In: Revista Brasileira de História. Sâo Paulo, vol. 30, $\mathrm{n}^{\mathrm{o}} .59,2010$, p. 238.

${ }^{10}$ Para uma história da União Brasileira dos Estudantes Secundarista, escrita em 2009, portanto após a publicação dos livros didáticos em análise, ver: CINTRA, A, MARQUES, R. L. de A. Ubes, Uma Rebeldia Consequente - A História do Movimento Estudantil Secundarista do Brasil . São Paulo: Ministério da Cultura, 2009 Disponível em: http://ubes.org.br/download/publicacoes/LIVRO-FINAL.pdf Acessado em 17/04/2017.
} 
enquadram numa perspectiva histórica preocupada em realçar a importância de "governantes e batalhas" e que valoriza as "grandes" mulheres que ocuparam posições tradicionalmente masculinas. A historiografia sobre o movimento estudantil, no período em tela, não destaca a participação de nenhuma mulher que tenha ocupado cargos de comando nas entidades estudantis ou que tenha tido um papel de liderança nas manifestações promovidas pelas mesmas. Como demonstraremos mais adiante, é recente a escrita de estudos sobre a história da participação feminina no movimento estudantil. Esta ainda precisa de um olhar mais atendo por parte das historiadoras e dos historiadores e, quem sabe assim, poderá chegar às páginas dos livros didáticos.

\section{As imagens como textos}

A busca da participação das mulheres no movimento estudantil nos livros didáticos se deu pela observação de textos - já comentados - e de imagens. Dos onze livros analisados seis veicularam imagens retratando as manifestações de rua, os confrontos entre estudantes do Mackenzie e da USP (SCHMIDT, 2005, p. 740) e a repressão das forças policiais (PEDRO; LIMA; CARVALHO, 2005, p. 749) ocorridas no Brasil no ano de $1968 .{ }^{11}$ Em três dessas imagens foi possível identificar a presença de mulheres.

Duas imagens em que aparecem mulheres se referem à chamada "Passeata dos cem mil”, ocorrida no Rio de Janeiro, em julho de 1968. No livro Rumos da História foi reproduzida uma foto dessa passeata na qual se destaca a presença de muitos homens e de algumas mulheres. Em frente à multidão estão os cantores Caetano Veloso e Gilberto Gil. Entre os dois, de braços dados com os mesmos, está uma mulher. Um homem, ao lado direito destes, segura um cartaz onde se pode ler "Artistas, intelectuais e o clero com os estudantes". Esta informação pode ser utilizada para ressaltar alguns dos grupos sociais que apoiavam as lutas estudantis. Na legenda da imagem se pode ler "Passeata dos Cem Mil, realizada no Rio de Janeiro em 1968” (REZENDE; DIDIER, 2005, p. 619). Nenhuma das pessoas presentes foi identificada, inclusive a mulher retratada.

O livro História traz uma imagem da mesma passeata, registrada por outro ângulo. Na legenda aparecem os nomes de vários "artistas e intelectuais" famosos. Além disso, pode-se

\footnotetext{
11 Neste estudo analisamos, preferencialmente, as imagens do movimento estudantil veiculadas junto aos textos que tratam desse tema, entre 1964 e 1968. Portanto, as imagens que fazem referência ao movimento estudantil publicadas em páginas que não tratam especificamente do assunto em tela ou que fazem referência ao movimento estudantil nos anos 1970 não foram analisadas.
} 
ler ainda que "os intelectuais e os artistas uniam-se aos estudantes na luta contra a ditadura militar." Ressalta-se o fato de que, entre as mulheres que aparecem na foto, somente a cantora Nana Caymmi foi nomeada (AZEVEDO; SERIACOPI, 2007, p. 481). Por esta segunda imagem e pela informação da legenda podemos afirmar que, na imagem do livro Rumos da História, mencionada anteriormente, a mulher que está de braços dados com Caetano Veloso e Gilberto Gil é Nana Caymmi. Como as imagens veiculadas estão centradas na linha de frente da passeata, formada por artistas e intelectuais, não foi dado destaque para a participação das/os estudantes na manifestação.

Na imagem veiculada no livro História: das cavernas ao terceiro milênio, percebe-se com destaque uma bandeira da UNE. Na legenda somos informados de que se trata de um “protesto estudantil na Avenida Borges de Medeiros, em Porto Alegre, em 4/7/1968, contra a repressão policial e política do regime militar, que provocou a morte do estudante Edson Luís numa manifestação no Rio de Janeiro" (MOTA; BRAICK, 2005, p. 159). Com certo esforço podemos perceber a presença de mulheres na fotografia, ainda que a legenda não chame atenção para o fato. Percebe-se também que a imagem e a legenda trazem uma informação que não está presente nos textos da maioria dos manuais analisados, qual seja, as manifestações contra a ditadura civil-militar ocorreram também fora do eixo Rio-São Paulo.

Em todas as capitais e centros universitários do país, conforme João Roberto Martins Filho, ocorreram manifestações por ocasião da morte do estudante Edson Luís (MARTINS FILHO, 2007, p. 195). Porém, ainda que os arquivos iconográficos mencionados nos manuais e das editoras dos mesmos estejam estabelecidos na capital paulista, somente um, dos onze livros analisados, utilizou uma imagem de uma manifestação ocorrida em São Paulo, no ano de 1968. Nela se destacam os policiais paulistas que fazem uso da força para dispersar uma manifestação estudantil. Na legenda podemos ler "A polícia reprime manifestação de estudantes em São Paulo, em agosto de 1968." Ao lado da imagem aparece a data “12/08/1968” e a informação "Foto AE” (PEDRO; LIMA; CARVALHO, 2005, p. 479). Nada nos é informado sobre estudantes feridos/as e presos/as pela repressão.

As imagens acima descritas trazem informações sobre o seu autor e o local onde estão arquivadas. O livro Rumos da História nos informa a autoria e a empresa jornalística proprietária da mesma. Ao lado da imagem pode-se ler "Campanela Neto/AJB” (REZENDE; DIDIER, 2005, p. 619). Possivelmente AJB seja a abreviatura de Agência Jornal do Brasil. No livro História, ao lado da foto, registrou-se "Wilton Júnior/Agência O Estado" 
(AZEVEDO; SERIACOPI, 2007, p. 481). A imagem veiculada no livro História: das cavernas ao terceiro milênio traz a seguinte informação "Fundo Última Hora/Acervo AESP" (MOTA; BRAICK, 2005, p. 159). Estas informações nos possibilitam várias inferências como: as equipes de pesquisa iconográfica das editoras de livros didáticos procuram as imagens em um ou vários arquivos; os acervos imagéticos estão ligados a empresas privadas, jornais que cobriam as passeatas na época, e instituições públicas, como o Arquivo Público do Estado de São Paulo; os bancos de imagens que forneceram as fotos que ilustram os textos sobre o movimento estudantil, assim como as editoras dos livros didáticos, estão localizados, em sua maioria, no estado de São Paulo. Entre as fotografias que compõem esses bancos de imagens, possivelmente, algumas retratam mais mulheres do que as que foram veiculadas nos livros didáticos analisados. Possivelmente, o fato dos textos dos livros didáticos excluírem as mulheres pesa no momento de selecionar as imagens que irão ilustrar os manuais escolares.

Como nos lembra Circe Bittencourt, o livro didático é antes de tudo uma mercadoria, "um produto do mundo da edição que obedece à evolução das técnicas de fabricação e comercialização pertencentes à lógica do mercado." Em sua construção, continua a autora, “interferem vários personagens, iniciando pela figura do editor, passando pelo autor e pelos técnicos especializados dos processos gráficos, como programadores visuais, ilustradores" (BITTENCOURT, 2001, p. 71). Ou seja, vários profissionais, homens e mulheres, interferem na produção dos livros didáticos.

As imagens que ilustram os textos que discorrem sobre o movimento estudantil denunciam a presença de mulheres nas manifestações estudantis que ocorreram em 1968. Porém, a mulher que aparece com mais destaque, inclusive tendo o seu nome registrado, é uma cantora e não uma estudante. Novamente podemos cotejar nossas analises com o trabalho de Ana Maria Marques, quando esta nos informa que os livros didáticos, além de destacarem as mulheres que ocuparam cargos e funções consideradas masculinas, destacam aquelas que alcançaram reconhecimento por sua atuação em diferentes campos do conhecimento acadêmico, por sua participação em movimentos artísticos e as mulheres que se sobressaíram na literatura e na música (MARQUES, 2015, 216). Essa opção por "mulheres de destaque", aliada a outros fatores, pode nos ajudar a entender o silêncio dos livros com relação às mulheres que participaram do movimento estudantil.

\section{A historiografia da participação feminina no movimento estudantil}


Diante da economia de informações sobre a militância feminina nas entidades estudantis e no movimento estudantil, notadamente nas mobilizações ocorridas entre 1964 e 1968, buscamos empreender uma pesquisa bibliográfica sobre estudos que abordassem a história dessa participação. Neste levantamento percebemos que já é considerável o número de trabalhos acadêmicos que versam sobre o tema. Por outro lado, quando se trata da atuação das mulheres em entidades estudantis e nas manifestações do movimento estudantil, verificase que as pesquisas ainda são escassas e que são poucos os textos publicados. Além disso, constatou-se que esses estudos se caracterizam, em sua maioria, por um recorte regional.

Ana Maria Colling publicou, em 1997, o livro A resistência da mulher à ditadura militar no Brasil. Nesta obra a autora analisa as várias formas de resistência empreendida por mulheres contra a ditadura militar, como o movimento estudantil, a participação em grupos clandestinos de esquerda que pegaram em armas ou não, as prisões e as torturas a que foram submetidas essas mulheres. Como referencial teórico Ana Colling fez uso da categoria gênero de análise. A metodologia da história oral foi empregada para entrevistar seis mulheres e três homens. Das mulheres entrevistadas, que nasceram no Rio Grande do Sul ou militaram nesse estado, a autora nos informa que, "somente uma não tinha participado do movimento estudantil.” (COLLING, 1997, p. 49). A autora não chegou a aprofundar uma história do movimento estudantil, porém, destaca a importância do mesmo como espaço de iniciação da mulher na militância política.

Ainda dos anos noventa, temos a dissertação de mestrado Marias do Socorro: Mulheres Presas, Mulheres Torturadas ${ }^{12}$ escrita por Marise da Silveira Veríssimo, que, apesar de também não ter como tema central o movimento estudantil, nos traz algumas informações sobre a militância política de mulheres de diferentes estados brasileiros, militância que inclui o movimento estudantil, secundarista e universitário. Das cinco mulheres entrevistadas três, Clair, Judite e Derlei, rememoraram suas participações no movimento estudantil.

Clair militou no movimento estudantil em Curitiba, em 1966. Ela informa que participou na organização dos estudantes, nas manifestações contra a política educacional do governo, por "uma universidade mais aberta e democrática", nas lutas contra a ditadura e

12 Ver: VERÍSSIMO, Marise da Silveira. Marias do Socorro: Mulheres Presas, Mulheres Torturadas. Florianópolis, 1998. 168 p. Dissertação de (Mestrado em História), UFSC, Florianópolis, julho de 1998. 
contra a forma de governo (VERÍSSIMO, 1998, p.58). Judite informa que militou somente no movimento estudantil secundarista, em Maringá, nos anos de 1967 e 1968. A entrevistada rememora que na época "Maringá era bem interior e tinha um movimento secundarista bastante forte". Judite lembra que participou de campanhas como a de solidariedade ao Vietnã, contra o acordo MEC-Usaid e o ensino pago. Ela recorda ainda que os secundaristas realizavam seminários de discussão que contava, em alguns momentos, com estudantes "de fora, que vinham fazer o trabalho político conosco" (VERÍSSIMO, 1998, p.90). Derlei, discorrendo sobre a sua atuação no movimento estudantil universitário em Florianópolis, menciona que "fazíamos muito comício relâmpago, para não sermos presos. Distribuíamos folhetos pela cidade e passávamos as madrugadas pichando muro: Vietnã vencerá na luta Abaixo a ditadura - Assalto aos bancos públicos - Estão roubando a UFSC" (VERÍSSIMO, 1998, p.105). A dissertação de Marise Veríssimo é um dos primeiros trabalhos sobre a temática da violência da repressão contra mulheres, escrito em Santa Catarina.

A historiadora Maria Paula Araújo publicou, em 2007, o livro Memórias Estudantis: da fundação da UNE aos nossos dias. Neste estudo a autora menciona que a participação das mulheres ocorreu desde os primeiros anos de fundação da UNE. Araújo destaca a importância dessa constatação devido ao fato de que, nas primeiras décadas do século XX, a maioria dos estudantes de cursos de nível superior, notadamente das faculdades mais prestigiadas, era composta por homens. Das mulheres esperava-se que se dedicassem integralmente ao lar e a família. A autora menciona ainda a luta das mulheres pelo direito à educação, pela emancipação feminina e pela conquista ao direito de votar e de ser votada. Como exemplo da participação feminina na UNE a autora cita a presença de mulheres no Congresso da UNE de 1948, ocorrido no Rio de Janeiro. A participação das estudantes naquele evento, destaca Araújo, dependeu em alguns casos da permissão de suas mães (ARAÚJO, 2007, p. 74-77).

A maioria das pessoas entrevistadas por Araújo para a escrita desse livro é composta por homens. No entanto, trazem informações sobre a militância feminina. Isto, certamente, está relacionado ao fato de que ao longo da história da UNE foram poucas as mulheres que participaram da direção da entidade. Em 1963, Maria Nazaré, uma militante da AP (Ação Popular), foi eleita para participar da diretoria da UNE (ARAÚJO, 2007, p. 145). Somente em 1982, nos estertores da ditadura, uma mulher foi eleita presidente da UNE, a baiana Clara Araújo, que já havia participado de duas gestões do DEC da UFBA (ARAÚJO, 2007, p. 240). 
Sobre a participação das mulheres nas lutas do movimento estudantil, no período em estudo, não foram feitas menções no livro.

Outro trabalho que narra a participação feminina no movimento estudantil é a história em quadrinhos 1968 ditadura abaixo, escrito pela jornalista paranaense Teresa Urban, com quadrinhos de Guilherme Caldas, publicado em 2008. Trata-se da história de jovens universitários, que estavam descobrindo a sexualidade, a agitação cultural e que participaram do movimento estudantil na cidade de Curitiba. A protagonista da história é uma jovem estudante inconformada com a qualidade da educação universitária da época. Após participar de pichações e passeatas, ela é presa é torturada pela polícia.

O livro foi escrito e desenhado com base nas memórias da autora sobre sua participação no movimento estudantil. Buscando contextualizar o momento cultural que marcou os anos de 1960, são reproduzidas notícias de jornais, propagandas de moda, cartazes de espetáculos culturais, documentos policiais, foto de mulheres em passeatas, entre outros.

A obra 1968 o tempo das escolhas, publicado em 2009, por sua vez, é o relato de memória escrito pela paulista Catarina Meloni. A autora militou no movimento estudantil, desde 1966, na USP, onde fazia o curso de Filosofia e Literatura. Em 1967 assumiu interinamente a presidência da UEE. Foi presa pelo DOPS paulista durante o desfile de Sete de Setembro, em 1968. Perseguida pela repressão, partiu com seu companheiro para o exílio, em 1972, após engravidar. Morou na Bolívia, de onde, em 30 dezembro de 1977, voltou para o Brasil.

Em 2012, Ingrid Faria Gianordoli-Nascimento, Zeidi Araujo Trindade e Maria de Fátima de Souza Santos publicaram Mulheres e militância: Encontros e confrontos durante a ditadura militar. Produzido a partir de referenciais teóricos da Psicologia Social, este livro foi escrito com base em nove entrevistas com mulheres que atuaram no movimento estudantil no estado do Espírito Santo, em dois períodos, entre 1964 e 1968 e de 1971 a 1972. Quatro delas, Sônia, Sílvia, Solange e Suzana, militaram no primeiro período, sendo presas em 1968.

Sílvia, devido à sua capacidade de articulação teórica e habilidade política, atuou como líder na organização e nas discussões sobre as passeatas e na redação de discursos e manifestos. Participou de manifestações contra o imperialismo americano e o acordo MECUsaid (GIANORDOLI-NASCIMENTO et al., 2012, p. 78). Solange traduzia textos considerados subversivos pela repressão, arrecadava fundos para o movimento estudantil e participou do Congresso da UNE em Belo Horizonte (GIANORDOLI-NASCIMENTO et al., 
2012, p. 100-101). Sônia, logo que entrou na universidade, foi escolhida líder do movimento estudantil. Foi vice-presidente da União Estadual dos Estudantes (UEE) passando a representar os estudantes capixabas nas ações nacionais (GIANORDOLI-NASCIMENTO et al., 2012, p.112). Suzana participou do Grêmio Estudantil e ao entrar na universidade, em 1967, sua militância se intensificou ao ser eleita presidente do Centro Acadêmico do seu curso (GIANORDOLI-NASCIMENTO et al., 2012, p.136-137). Através das entrevistas foram registradas as trajetórias dessas mulheres que, devido à militância política, foram presas e torturadas pela ditadura militar no Brasil.

Mais recentemente, Lidia Schneider Bristot escreveu um trabalho de conclusão de curso intitulado Mulheres no Movimento Estudantil de Florianópolis (1975-1979). ${ }^{13}$ Este estudo apresenta algumas informações sobre a participação de mulheres no movimento estudantil nos anos de 1967 e 1968, em Santa Catarina. Apesar de seu estudo ter como foco principal o período compreendido entre os anos de 1975 e 1979, Bristot relata, entre outras questões, que a delegação de Santa Catarina no Congresso de Ibiúna, em 1968, era composta por 15 delegados/as, sendo três mulheres: Derlei Catarina de Luca, Rosemeiri Cardoso e Gilda Laus. Quando retornaram para Florianópolis, todos/as os/as estudantes passaram a ser monitorados pelos órgãos de repressão (BRISTOT, 2014, p. 28). Entre os líderes mais atuantes do movimento estudantil catarinense, relata a autora, estava a estudante Derlei Catarina de Luca, ligada à Ação Popular (AP). ${ }^{14}$

Isadora Ritterbusch Librenza desenvolveu a pesquisa História oral da militância feminina no movimento estudantil: a trajetória de entrevistadas do Projeto Marcas da Memória (1964-1969), para a qual utilizou entrevistas realizadas pela professora Maria Paula Araújo para o Projeto Marcas da Memória, do Ministério da Justiça. ${ }^{15} \mathrm{O}$ objetivo foi analisar e descrever a trajetória de mulheres que militaram no movimento estudantil nos primeiros anos da ditadura civil-militar, em diferentes estados brasileiros. Partindo das memórias das militantes, captadas através da metodologia da história oral, a pesquisa abordou temas como a influência dos familiares na militância dessas mulheres, as escolas como espaços de formação

13 Ver: BRISTOT, Lidia Schneider. Mulheres no Movimento Estudantil de Florianópolis (1975-1979). Florianópolis, 2014. Trabalho de Conclusão de Curso (História) - Departamento de História - Centro de Ciências Humanas, Universidade Federal de Santa Catarina, 2014.

${ }^{14}$ Sobre a atuação da Ação Popular em Santa Catarina ver: SCHLATTER Jr. Sérgio Luis. Ação Popular em Santa Catarina: uma história entre afetividades e militâncias. Revista Santa Catarina em História - Florianópolis - UFSC - v.5, n.2, 2011

15 Ver: LIBRENZA, Isadora Ritterbusch. História oral da militância feminina no Movimento Estudantil: a trajetória de entrevistadas do Projeto Marcas da Memória (1964-1969). 2014. 64F. Trabalho de Conclusão de Curso (História) - Instituto de Filosofia e Ciências Humanas, Universidade Federal do Rio Grande do Sul, Porto Alegre, 2014. 
política, as atividades desenvolvidas pelas mulheres no movimento estudantil, as prisões a que estiveram sujeitas e a entrada nas organizações clandestinas de esquerda, que optaram pela luta armada ou não.

Como podemos perceber na descrição acima, somente os dois primeiros trabalhos citados foram escritos ainda nos anos 1990. Portanto, antes de 2005, data da publicação dos livros didáticos por nós analisados. Assim sendo, a escassez de trabalhos apresenta-se como um dos fatores para entendermos o porquê dos livros didáticos não abordarem a história da participação feminina no movimento estudantil.

Nota-se que a bibliografia coligida é bastante diversificada, composta por relatos de memórias, escritos pelas próprias ex-militantes, e trabalhos acadêmicos, publicados em livros ou não. Destaca-se o fato de que a metodologia predominante empregada na elaboração dos trabalhos acadêmicos é a história oral. As discussões teóricas sobre memória e gênero também estão presentes. Isso nos remete para a importância da história oral e das reflexões sobre gênero e memória na construção de uma história que incorpore a presença das mulheres na história do movimento estudantil. Um das características dos estudos elencados é o fato de abordarem as histórias de mulheres que militaram no movimento estudantil em diferentes estados brasileiros. Se esses recortes regionais parecem dar a ideia de uma história bastante fragmentada, eles têm a vantagem de romper com as narrativas muito centradas nos eventos de São Paulo e do Rio de Janeiro, como aquelas que apareceram nos livros didáticos.

Não é nosso objetivo, ao mencionar esses trabalhos, apresentar um quadro completo sobre as produções referentes ao tema. Ele serve para nos mostrar que o interesse pelos estudos sobre a participação feminina no movimento estudantil, entre 1964 e 1968, está crescendo no país. Além disso, os/as professores/as exercitando o seu protagonismo podem recorrer a essa bibliografia para trabalhar em sala de aula a história da participação feminina no movimento estudantil.

\section{Considerações Finais}

A história do movimento estudantil divulgada nos livros didáticos ainda é bastante fragmentada e resumida. As narrativas e imagens se concentram, na maioria das vezes, nas manifestações ocorridas em 1968, notadamente no Rio de Janeiro. Em geral os manuais descrevem a UNE como sinônimo de movimento estudantil. Pouco nos foi informado sobre a 
participação de outras entidades estudantis, universitárias e secundaristas, nas manifestações da época. Os estudantes são descritos nos textos analisados como sendo homens e jovens. $\mathrm{Ou}$ seja, a história do movimento estudantil veiculada nos livros didáticos estudados ainda é androcêntrica.

Dos onze livros analisados somente um mencionou a presença das "meninas" do movimento estudantil, rompendo, mesmo que brevemente, com o uso recorrente de termos genéricos masculinos, entre os quais "os estudantes" e "os jovens".

Alguns manuais reproduzem imagens de mulheres. Nestas se destacou, pelo ângulo da foto ou pelo registro do nome, a presença de uma mulher ligada ao mundo da música. Somente um dos livros didáticos analisados apresentou uma foto onde uma mulher aparece próxima de uma bandeira da UNE, numa manifestação de rua ocorrida na cidade de Porto Alegre, em 1968. Esta imagem, que porta informações que não estavam presente no texto do livro didático, não foi explorada no sentido de chamar a atenção dos/as leitores/as para a presença feminina no movimento estudantil.

Alguns fatores podem nos ajudar a entender a ausência da história das mulheres no movimento estudantil, nos livros analisados: até 2005, ano da publicação dos livros distribuídos pelo PNLEM/2008, este tema foi pouco abordado pelas/os historiadoras/es; o uso rotineiro de substantivos masculinos na língua portuguesa para representar homens e mulheres encobre o protagonismo feminino; a menor presença de mulheres na direção da UNE, associada à supervalorização desta entidade nos relatos, contribui para que o foco não seja dirigido às mulheres; o espaço restrito que os manuais reservam a cada um dos temas tratados implica em escolhas que, por sua vez, dialogam com os outros fatos acima mencionados.

Constatamos de forma alentadora, no entanto, que a temática em tela vem merecendo cada vez mais atenção por parte de pesquisadoras/es e de ex-militantes que escrevem sobre suas memórias. Estes trabalhos, certamente, podem contribuir para romper o silêncio, presente em muitas salas de aulas, em torno da participação das mulheres nas lutas estudantis e em muitos outros episódios da história recente do Brasil.

\section{Fontes - Livros didáticos analisados - Distribuídos pelo PNLEM/2008}

AZEVEDO, Gislane Campos Azevedo \& SERIACOPI, Reinaldo. História. São Paulo: Editora Ática, 2007.

BRAICK, Patrícia do Carmo R.; MOTA, Myriam Becho. História: das cavernas ao terceiro milênio. Vol. 3. São Paulo: Editora Moderna, 2005. 
CAMPOS, Flávio de; MIRANDA, Renan Garcia. A escrita da História. São Paulo: Editora Escala, 2005.

COTRIM, Gilberto Vieira. História Global: Brasil e geral. São Paulo: Editora Saraiva, 2005.

FIGUEIRA, Divalte Garcia. História. São Paulo: Ática, 2005.

LIMA, Lizânias de Souza; CARVALHO, Yone de; PEDRO, Antonio. História do Mundo Ocidental. São Paulo: Editora FTD, 2005.

MORAES, José Geraldo Vinci de. História Geral e do Brasil. São Paulo: Atual, 2005.

OJEDA, Eduardo A. B.; PETTA, Nicolina L.; DELFINI, Luciano Emidio. História: Uma abordagem integrada. São Paulo: Editora Moderna, 2005.

REZENDE, Antonio Paulo; DIDIER, Maria Thereza. Rumos da História. São Paulo: Editora Atual, 2005.

SCHMIDT, Mario Furley. Nova História Crítica. São Paulo: Editora Nova Geração, 2005.

SENIZE, Maria Helena V.; PAZZINATO, Alceu. História Moderna e Contemporânea. São Paulo: Editora Ática, 2005.

\section{Referências}

ARAÚJO, Maria Paula Nascimento. Memórias Estudantis, 1937-2007: da fundação da UNE aos nossos dias. Rio de Janeiro, Relume Dumará/Fundação Roberto Marinho, 2007.

Betinho (Ebert José de Souza) In: UCHÔA, Pedro Celso; RAMOS, Jovelino. Memórias do exílio - brasil 1964/19?? Vol.1 De muitos Caminhos. São Paulo: Editora Livraria Livramento Ltda., 1978, p. 74.

BITTENCOURT, Circe M. Livros didáticos entre textos e imagens. In: BITTENCOURT, Circe M. (org). O Saber histórico na sala de aula. São Paulo: Contexto, 2001.

BRISTOT, Lidia Schneider. Mulheres no Movimento Estudantil de Florianópolis (19751979). Florianópolis, 2014. Trabalho de Conclusão de Curso (História) - Departamento de História - Centro de Ciências Humanas, Universidade Federal de Santa Catarina, 2014.

CINTRA, André; MARQUES, Raisa. Ubes, Uma Rebeldia Consequente - A História do Movimento Estudantil Secundarista do Brasil . São Paulo: Ministério da Cultura, 2009. Disponível em: file:///C:/Users/Usuario/Downloads/LIVRO-FINAL.pdf (acesso em 17/04/2017)

COLLING, Ana Maria. A resistência da mulher à ditadura militar no Brasil. Rio de Janeiro: Record/Rosa dos Tempos, 1997.

De LUCA, Derlei Catarina. No corpo e na alma. Criciúma: ed. do autor, 2002.

GIANORDOLI-NASCIMENTO, Ingrid Faria; TINDADE, Zeidi Araujo; SANTOS, Maria de Fátima de Souza. Mulheres e militância: encontros e confrontos durante a ditadura militar. Belo Horizonte: Editora UFMG, 2012.

História. Catálogo do Programa Nacional do Livro Didático para o Ensino Médioio. Brasília: Ministério da Educação/Secretária da Educação Básica, 2007. 
KNAUSS, Paulo. Por onde anda a história na atualidade da escola: Ensino Médio, livros didáticos e ensino de história. IN: ROCHA, Helenice; MAGALHÃES Marcelo \& GONTIJO, Rebeca (Orgs.). A escrita da História escolar - memória e historiografia. São Paulo: Editora FGV, 2009.

LIBRENZA, Isadora Ritterbusch. História oral da militância feminina no Movimento Estudantil: a trajetória de entrevistadas do Projeto Marcas da Memória (1964-1969). 2014. 64F. Trabalho de Conclusão de Curso (História) - Instituto de Filosofia e Ciências Humanas, Universidade Federal do Rio Grande do Sul, Porto Alegre, 2014.

MARQUES, Ana Maria. Gênero e Ensino de história: Estudo sobre livros didáticos e práticas docentes no ensino médio. In: PARENTE, Temis Gomes, MIRANDA, Cyntia Mara (orgs.). Arquiteturas de gênero: questões e debates. Palmas, TO: Un. Federal de Tocantins/EDUFT, 2015.

MARTINS FILHO, João Roberto. O movimento estudantil nos anos 1960. In: FERREIRA, Jorge; REIS, Daniel Aarão (orgs.). Revolução e democracia: 1964-... Rio de Janeiro: Civilização Brasileira, 2007.

Campinas: Papirus, 1987.

Movimento estudantil e ditadura militar: 1964-1968.

Campinas: Mercado das Letras, 1996.

MELONI, Catarina. 1968 - o tempo das escolhas. São Paulo: Nova Alexandria, 2009.

MENDES Jr, Antonio. Movimento Estudantil Brasileiro. São Paulo: Editora Basiliense, 1981.

MACHADO, Vanderlei. Está faltando ela: a história da resistência feminina ao regime militar nos livros didáticos de História. 2008. Disponível em: http://eeh2008.anpuhrs.org.br/resources/content/anais/1208726223_ARQUIVO_EstafaltandoEla.pdf (acesso em $02 / 05 / 2014$ )

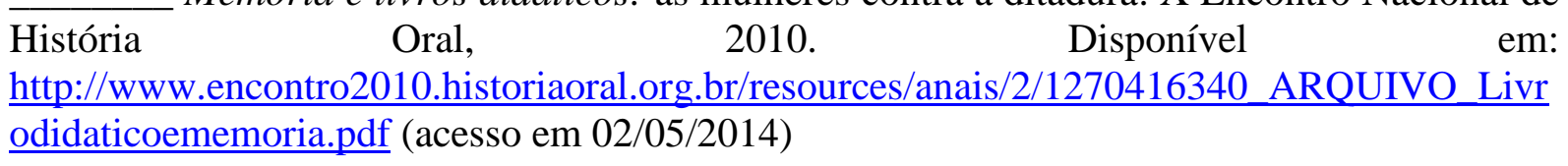

MOTTA, Rodrigo Patto Sá. Modernizando a repressão: a Usaid e a polícia brasileira. In: Revista Brasileira de História. São Paulo, vol. 30, nº.59, 2010.

MÜlLER, Angélica; REZENDE, Tatiana Mato. Praia do Flamengo, 132: Histórias e Memórias. São Paulo: Letras Jurídicas, 2011.

PRIETTO, Bernard G. Entre Rejeitados e Separados: o movimento estudantil no Correio do Povo. Uma análise do discurso sobre os "problemas estudantis" no Rio Grande do Sul (1968 - 
1969). 2011. 67f. Trabalho de Conclusão de Curso (História) - Instituto de Filosofia e Ciências Humanas, Universidade Federal do Rio Grande do Sul, Porto Alegre, 2011.

RODEGHERO. C.S.; MACHADO, V. A História recente nos livros didáticos de História: a ditadura militar e a questão da anistia no Brasil. In: Cadernos do Aplicação (UFRGS), v. 23, p. 165-198, 2010.

SILVA, Cristiani Bereta da. Gênero e sexualidade nos livros didáticos de História: Algumas questões sobre produções de subjetividades. 2006 Disponível em: http://www.fazendogenero.ufsc.br/7/artigos/C/Cristiani_Bereta_da_Silva_07_A.pdf. Acessado em: 30.04.2011.

SCOTT, Joan. Gênero: uma categoria útil de análise histórica. IN: Educação \& Realidade, vol.20, n.2. julho/dezembro 1995.

SCHLATTER Jr. Sérgio Luis. Ação Popular em Santa Catarina: uma história entre afetividades e militâncias. In: Revista Santa Catarina em História - Florianópolis - UFSC v.5, n.2, 2011

URBAN, Teresa. 1968 ditadura abaixo. Curitiba: Arte \& Letra, 2008.

VENTURA, Zuenir. 1968: o ano que não terminou. São Paulo: Nova Fronteira, 1988.

VERÍSSIMO, Marise da Silveira. Marias do Socorro: Mulheres Presas, Mulheres Torturadas. Florianópolis, 1998. 168 p. Dissertação de (Mestrado em História), UFSC, Florianópolis, julho de 1998.

\section{Anexo I \\ UNIVERSIDADE FEDERAL DO RIO GRANDE DO SUL COLÉGIO DE APLICAÇÃO - DEPARTAMENTO DE HUMANIDADES}

PESQUISA: A História das mulheres que os livros didáticos não contam: as lutas femininas contra a ditadura militar no Brasil

ORIENTADOR: Vanderlei Machado BOLSISTA DE INICIAÇÃO CIENTÍFICA:

Alessandro Güntzel

Roteiro de Avaliação Livro Didático

Título do Livro:

Autor/a:

Cidade, Editora e Ano de Publicação:

Número e Título do Capítulo Analisado:

Página inicial e final do capítulo: 
Subtítulos e número da página correspondente:

Os textos discorrem sobre a participação feminina no movimento estudantil ( ) Sim ( ) Não

Caso mencionada, a participação feminina nos eventos narrados:

( ) aparece no texto principal ( ) aparece nos chamados boxes?

Em seu texto o autor: ( ) usa termos no masculino genérico ( ) Se dirige a homens e mulheres

O capítulo tratado possui imagens? ( ) Sim ( ) Não

Em quantas imagens aparecem ( ) mulheres ( ) homens ( ) Homens e Mulheres

Descreva as imagens e informe o subcapítulo em que elas aparecem:

Transcreva as legendas das imagens:

A imagem tem relação com o texto principal?

O capítulo analisado apresenta uma bibliografia sobre a História das Mulheres no movimento estudantil ( ) Sim ( ) Não 